\title{
Discussion
}

Three discussion periods covered most of the major topics related to the organization and staffing of casualty services. It was thought unnecessary to publish these in full. The subject matter has therefore not only been considerably abbreviated, but has also been liberally edited, in order to bring it under specific headings. This inevitably leads to some of the material lying out of sequence in the context of the meeting as a whole, but much of this material is important and is more accessible when presented in this manner. Loss of sequence $i$, thought to be a small price to pay for this.

\section{The call for statistics}

Mr STEEL: I am concerned that the introduction of a casualty consultant is a radical solution and that we are being pushed into this solution with inadequate data. I would like to challenge $\mathrm{Mr}$ Aldridge on his $45 \%$ of medical cases in the accident and emergency department. Recently I did a survey in Stoke-on-Trent which has an accident and emergency department with over 60,000 attendances a year. We looked at a 4-day period with 650 attendances and the figures break down into $80 \%$ trauma and $20 \%$ non-trauma. Of the non-trauma, $7 \%$ was medical. Of the trauma, $70 \%$ was locomotive trauma and $7 \%$ was foreign bodies in the eye.

Mr WAINWRIGHT: Can I just support my colleague? Two years ago I conducted a survey of the accident services in the Birmingham region and I was struck by two things. Firstly, the tremendous variation in the type of work in different departments, and secondly, the lack of information and statistics. I do not think we can sort out this problem until we have much better statistics. I think the Department of Health and the regional boards must provide the larger hospitals with proper clerical facilities for providing good statistics of the needs of the accident service in their districts. We must know these figures very accurately before we can plan our services.

Mr CARo: I think the most important thing about statistics is that numbers are not enough. Minor trauma, with adequate supervision and good organization, takes a relatively short time. The medical cases, although a small percentage, take a much longer proportion of time per case. What is traumatology and what is accident and emergency work? We must clarify this from the beginning. Traumatology is what Mr London does at the Birmingham Accident Hospital. Our main problem at Balham is different from this. Our main problem is coping with the large mass of accident and emergency cases which appear mostly in the main metropolitan departments. The Casualty Surgeons' Association defines their function as dealing with all patients who find themselves in an emergency situation who are not able to use the normal GP services.

MR ALDRIDGE: The time taken is certainly very important but unfortunately only numerical statistics are available. A survey from the City of Birmingham hospitals showed that $40-45 \%$ of cases are non-traumatic and these $40 \%$ are cases that we thought to be appropriate to general practice but the situation does vary enormously from area to area. The statistical department of the
Birmingham Regional Hospital Board are at present carrying out an analysis of the patients attending the accident and emergency department at Wolverhampton. This is a day-to-day prospective survey of the time involved, the type of case, where it has come from, whether they have tried to get a doctor, whether it was appropriate for them to attend at that particular time and so on.

MR WAINWRIGHT: Any big area planning an accident service must start by getting a good survey. To do this we need added clerical help.

The differences between areas were later emphasized by Doctor Bainbridge

DR BAINBRIDGe: From our survey we have ninety major departments with less than 15,000 new cases a year and at the other extreme we have twenty-five units of over 40,000 a year. In between we have all grades. These departments have grown up in many varied positions. The practices that have built up over the years in each of these will also be very different. Thus, it is the responsibility of local people to put up solutions applicable to their own area.

In a more specific way these differences were emphasized by $\mathrm{Mr}$ Denham the following morning.

In answer to the question by Mr Wilson: 'Could I ask Mr Denham who it is that copes with the other urgent problems like putting in chest tubes and doing tracheostomies in his department?'

MR DENHAM replied-'The orthopaedic staff cope with these. I do not think it matters who does them as long as the duties are well-defined and as long as your area organization is focussed on the person who is doing it. I think the idea of an accident surgeon who can cope with trauma to all systems is all very well if you work, like Peter London, in an accident hospital in a big town. There is, however, no room for an accident surgeon in a town of half a million people. The occasional splenectomist in Portsmouth would be a disaster.'

Mr CARO: Nor do I think there is a place for an accident hospital in a big conurbation like London. You have the problem of where to put the hospital and how to get your patient to it.

\section{Defining the problem of organization}

Mr O'ConNor: We must decide who is going to look after accident surgery, who is going to look after medical emergencies, who is going to look after general surgical emergencies, how to provide services in the big conurbations and in holiday and sickness situations. We must get that clear now and $I$ think that the attitude of the Department of Health is to assume a situation which covers the entire spectrum. They have not in fact defined the problem.

DR BAINBRIDGE: I think we have. We are agreed that the new casualty surgeon will deal with primary care and not with definitive treatment. Therefore, we are not expecting him to deal with trauma, he will in fact be an expert in 
triage* and resuscitation. We appreciate that the work load will vary from place to place. This is absolutely clear from what people have said already and this is why we are saying that before any job is agreed, people on the ground should look at their casebook and see what happens to their patients-how many are admitted, what percent are medical, what percent are paediatric and so on. When they have done this, and only then, can we find the job that needs to be done in their area. This is what we are trying to get at.

Mr O'CONNOR: If an orthopaedic surgeon is prepared to look after traumatic cases he should assume responsibility for their initial reception and resuscitation. The same applies to the general surgeon who wants to look after surgery and general surgical emergencies and to a physician. But who is going to look after the wide spectrum of general practice problems? I do not think you are going to find any one expert who is going to cover this spectrum of activities.

DR BAINBRIDGE: What we are trying to do at the moment is to have someone who is responsible for the triage and resuscitation. If, when the consultants get together there is a particular group of patients who are particularly well catered for, it may be trauma, it may be coronary care, then obviously local arrangements must take this into consideration. We want to improve the service, not to create difficulties. If the orthopaedic surgeons are prepared to look after trauma, and if the general surgeons are willing to look after their emergencies, and the general physicians look after theirs, this is fine. But surveys show that $20 \%$ of accident and emergency departments do not have a consultant surgeon entering the department, let along being 'on call'. This is the kind of situation we are attempting to deal with. Where there are good departments we do not wish to upset them and if all departments had reached this standard of excellence our Symposium might be taking an entirely different form.

The need for an overall plan with defined objectives was emphasized the following morning during the discussion of a different problem.

Mr RosE: There is no overall authority who says that the demand of the patient over-rules the situation, and somehow we have got to break through this. We have got to make a structure which fits our needs. If anything at all comes out of this weekend it will surely be that authority is made aware of the problems which face us in organizing these departments. Then perhaps it may be seen that a major re-organization is required.

Mr O'CONNOR: I think it has been made very clear that somebody has got to step in and make a major reorganization.

\section{The sorting or triage problem}

DR PLEDGER: The central problem is consultant cover. If we are going to accept the accident and emergency service as being the front line, then you either have your streaming into specialties with your sister as sorter (which I do not think is a good idea) or we have to find some other way to decide who is the consultant in charge. The suggestions put forward this afternoon generally

$$
\text { *Triage-sorting by quality (O.E.D.). }
$$

reflect the medical point of view that most emergencies are a rather trivial problem and that working in the emergency department is of poor standing in the professional sense. You will either have a man who is called a consultant but is not a consultant calling for help from other people or, as the BOA would like to have, a consultant in charge but not actually doing anything in the department. We are just perpetuating the situation that accident and emergency work is a second-rate job and a second-rate problem. This pervades medical students and staff and this is why we cannot find recruits. The vicious circle has to be broken down and the job enriched.

The fact that sorting is work for an experienced doctor had been earlier emphasized by Mr Caro.

Mr CARO: Mr O'Connor has simplified the problem when dividing patients into surgical, medical and so on. They are not categorized until they have been sorted. This is a critical matter. The crux of the problem is how to separate the minor from the major problems. Although resuscitation comes in later, the prime problem is in recognizing the ill patient. You may say that this is a general practitioner problem, but when it presents in the emergency department it has passed that stage.

Later in the discussion however, $\mathrm{Mr}$ Caro seemed to accept that nurses had a bigger part to play in the total management of the patient than was at present envisaged.

Mr CARo: I would agree with Mr Denham wholeheartedly on the lack of use of our nurses. It happens in works surgeries; it happens in cottage hospitals; why should it not happen in our accident departments? I should like to ask Doctor Bainbridge about this.

DR BAINBRIDGe: This is a legal problem. Nurses are not trained to make a diagnosis. We have said in our circular, HM 68/83, that the sorting is not to be carried out by nursing staff. This is the legal position and I do not think at the moment that anybody is going to change it. It is one of those things, 'If you want to do itgo ahead; but if it lands you in trouble, do not expect any support'.

MR Rose: It just shows how we organize our hospitals along totally unrealistic lines.

Mr Witherow: This is not a legal requirement. It is the regulation of the Department of Health. If, as the result of sorting by a nurse, the hospital is sued, the hospital is responsible. If however, the doctor is sued, it is the Medical Defence Union that pays. The regulation that a nurse should not be allowed to sort patients is one of the biggest difficulties in re-organizing the departments.

DR BAINBRIDGE: If you are prepared to train them and state that they are competent to take responsibility for that action, then they may stitch etc., but they should be seen initially by a doctor. It is not the Department of Health that changes but the attitude of the general public. The general public expects to be seen by a doctor.

DR PleDger: As far as I know the document issued by the Department of Health is not a legal document and this implies that a doctor is entitled to delegate responsibility to a nurse and accept this responsibility. Until this is tested in court, you cannot say that it is illegal.

Mr CARo: It is through orders of the matron that nurses are prevented from doing these things. 
DR BAINBRIDGE: We must recognize that, like social workers, nurses are developing a professional responsibility so that they are defining their terms of reference more clearly.

Mr Hampson: I do not think the British public always expects to see a doctor. I think they are prepared to see a nurse and receive first aid treatment at night, returning the next morning for their X-rays. We can get round the legal aspect by asking the patient to sign a form stating that they accept this treatment.

\section{General practitioner/hospital relationships}

In country areas, sorting is inevitably carried out to a large extent by the general practitioner. In towns it is often very difficult for the general practitioners to make a significant contribution, even if they want to. These relationships between the general practitioner and the hospital were considerably explored during the discussion. They are summarized by Mr Spivey.

Mr SPIVEY: We have had many different points of view put forward and it is time for these to be discussed together. I think it is pointless that the BOA can discuss casualty and accident services in isolation. I think the Casualty Surgeons' Association is at a disadvantage because of its size and I believe that the GPs have a very important role to play in hospitals in the accident and emergency department depending upon the local need. All those actively engaged should try to get together rather than leaving it to the BOA or the BMA to try to rationalize the situation. Each community has a different need, and at the moment orthopaedic surgeons are falling down on the job.

Earlier Mr Wainwright had tried to clarify the Department of Health's attitude to GPs taking a greater part in the care of minor emergencies.

Mr WaINWRIGHT: What discussions have the Ministry had with representatives of the general practitioners about their part in the care of emergencies? It does seem that if minor emergencies could be treated in health centres a great deal of the burden and difficulties of organizing departments would disappear. Has this got very far?

DR BAINBRIDGE: One of the solutions would be to treat patients in health centres, the responsibility of a doctor in a health centre is no different from that in a group practice; they have no definite responsibility and, where they have attached local authority services, this occurs only during the working day. They would therefore be unable to help with night cases. This could be reorganized but it will have to depend upon the development of health centres and at the present time would be impossible within the tripartite health system.

MR WAINWRIGHT: It is common practice to have emergency centres in cottage hospitals surrounding the main hospital. There is no reason why general practitioners should not treat minor emergencies in these places.

DR BAINBRIDGE: In a recent survey we were able to look at returns from 300 out of 401 peripheral departments of the type that you mentioned. This shows that about $70 \%$ of them were staffed by general practitioners. I agree that if we can get this type of service working in the conurbations this would be a major advance. How- ever, I am told that general practitioners are moving out of the centre of cities and that they are making increasing use of the emergency 'on call' services. They also have appointment systems which generally work very well but increasingly we hear reports that receptionists can be difficult when dealing with requests to see emergency cases. All these factors are militating against the patient using the general practitioner services. What is more, the GP emergency 'on call' services are often being manned by hospital doctors who do not know the local situation and are therefore referring the patient back to the hospital emergency department.

\section{Later this problem was raised again by Mr Steel.}

Mr STEEL: I think Doctor Cull has suggested a solution to the other half of the problem. This is the development of health centres with emergency departments staffed by general practitioners. We have calculated that if these departments could be manned between 9 in the morning and 8 in the evening it would reduce our work load by $50 \%$. If you provided them with a simple $X$-ray unit and a nurse to put a stitch in, a lot of these problems would be solved.

DR CULL: I think if you provide him with a sterile tray this would make things considerably easier.

MR DURBIN: I think if you provide him with X-ray facilities you have a medico-legal problem. However, if you had these X-rays collected twice a week, and read by a radiologist at the hospital, the problem could be overcome. I do not think any real harm could develop as the result of injury to an extremity if it was missed for only 2 or 3 days.

With regard to the provision of sterile trays Doctor Aldridge later said:

'Concerning the provision of sterile equipment to peripheral accident units, such as one might find in a GP health centre, we have had some political difficulty in introducing this in the Birmingham region. We are now making a slow start with this idea.'

DR PARK: With regard to the provision of X-ray facilities I would be hesitant about the advisability of allowing expensive unsupervised X-ray equipment to be placed in health centres.

DR Cull: I agree entirely. I am not in favour of radiology at health centre level but rather that we should have open access to X-ray departments in the hospital.

The contribution of GPS to emergency services was further discussed by Mr Mulholland.

Mr Mulholland: I wonder whether general practitioners could be persuaded to work in a casualty department. What evidence have we that general practitioners will provide emergency services in their health centres?

DR Cull: It is very difficult for general practitioners to do casualty sessions due to their clinics and surgeries which they have to run as part of their practice. It is easier to treat emergencies within my own health centre, where I am usually available, than to come to the emergency department at the main hospital some distance away. 
Mr Mulholland: The government have provided financial and building facilities for further care of patients within the community by general practitioners. The general practitioners remain in Victorian buildings despite this offer by the government. How far do you think the general practitioners have failed to cope with their responsibility?

DR Cull: This is not quite true. There is no advantage in up-grading old buildings. You have to plan a new department to cope with the developing situation. These must be properly designed units.

MR MULHOLlaND: Is there any evidence that providing facilities in health centres has reduced the work load in the casualty department?

DR CULL: I cannot tell you about this.

Mr Durbin then drew our attention to a recent paper in the British Medical Journal which pointed out that it was not economic for a health centre to provide emergency services during the nights and weekends.

MR O'CONNOR: I do not think the general practitioners want to become involved in emergency work unless they are paid accordingly - for instance by an item of service arrangement.

DR BAINBRIDGE: Where there is agreement locally, and with the recommendation of the local executive committee, we have encouraged the development of health centres. I agree that with the attachment of local authority staff and treatment rooms a lot of primary care could be carried out; but my general practitioner friends would not like to encourage the view that health centres have been used as an emergency department because in some instances this is preventing further general practitioners from participating in health centres. At the inception of the National Health Service in 1948 some health centres with elaborate facilities were set up. However, with the development of the health centres these were looked at again and we have found many of the facilities were underused. The health centre is now being planned and the Regional Hospital Board is asked for their opinion as to where the special facilities should be provided. This is only done under special circumstances and when there is a very special need, for instance if local hospital facilities are poor or if the health centre is built in a new town.

MR WILSON: I think I may be the only orthopaedic surgeon here who is working in a health centre. I have seen many of the minor surgical problems dealt with in the health centre and I am sure that this has taken a considerable load off our casualty department.

DR CULl: How many doctors work in this health centre?

Mr WILSON: Ten doctors, but not devoting the whole of their time there.

\section{Casualty consultant appointments}

The current implementation of the Department of Health's Plans to appoint a number of casualty consultants as a trial provoked a great deal of discussion. Doctor Bainbridge pointed out in these words that having somebody senior in the casualty department would not only simplify the sorting problem in hospitals but would also improve the GP/hospital relationships'.
'If you had somebody senior working in the department they have

(a) more authority to speak to the patient;

(b) personal contact with the general practitioner, so that the administrative policy of the unit will become known'. This is something which a senior house officer working 6 months cannot do.

MR WILSON: Accident and emergency services are working $24 \mathrm{hr}$ and the heaviest load comes in after the normal working day. I cannot see how a casualty surgeon appointed to oversee an emergency department working 9-5 and not weekends can play any useful part in the department whatever.

DR BAINBRIDGE: We do not envisage one casualty surgeon managing by himself; he has to be supported by other consultants. He will need an infrastructure within his department with his own senior registrar and registrar where appropriate.

Later Mr Wroblewski (Birmingham) expressed his doubts about the necessity of running the so-called 'pilot scheme'.

MR WROBLEWSKI: If you want a proper career structure you need somebody in charge of casualty with a status equal to others in the hospital who have departmental responsibility. He has to be somebody who is a consultant. There are pilot studies using this type of organization which have been going on for 20 years. Figures may be obtained from these departments without starting a whole new set of pilot schemes to be run by the Department of Health.

DR BAINBRIDGE: In fact in these pilot schemes the casualty surgeons will be of equal status, at this moment we have not got any one group of people working in our hospitals, orthopaedic surgeons, general surgeons, anaesthetists, whoare prepared to undertake this work. In the advertisements there will be no difference between these appointments and any other consultant in the hospital.

Later Mr Durbin expressed doubt as to whether the appointment of a casualty consultant was a satisfactory solution.

Mr DURBIN: I agree with $\mathrm{Mr}$ Caro that we require an experienced man in the emergency department at all times but you cannot have a consultant in a department for $24 \mathrm{hr}$ in the day.

Mr CARo: If you are in charge of the department and you are not there, then you must make sure that the responsibility has been delegated to somebody else. The problem of getting somebody senior there at night is not nearly so difficult as during the day. I acknowledge that much of the work I do during the day is done by registrars at night; they are not easily available during the day. My people are trained to call the right person at the right time or to ask me if they are in difficulties. I do not pretend to be there all the time but my influence prevails in the department and I hope it ensures that the department runs smoothly.

Mr DURBIN: The consultant has to have doctors who are under him and, while in certain of the larger centres he would be able to get these, this staffing structure cannot 
prevail over the whole of the country. Sixty percent of the hospital departments have a small intake of 25,000 or less, and this structure would not work in these departments. There are twenty-five hospitals with an intake of over 40,000 new patients a year and you might appoint casualty consultants there.

Mr CARO: You cannot put a casualty officer in one small peripheral unit and isolate him there. He must be rotated through the main centre so that he knows what to do and knows whom to call for help. This man is an integral part of a comprehensive accident and emergency service.

Thus, there were fears as to whether the new casualty consultant could solve any of the problems either of organization or staffing for the full $24 \mathrm{hr}$ of the day for which the solutions were required.

Mr WAINWRIGHT: Would you not envisage divided responsibility in the immediate care of the patient?

DR BAINBRIDGE: If the sorter decided that the case was an orthopaedic responsibility he would call the orthopaedic surgeon's representative who would probably already be in the accident department. The case could then be easily handed over following the initial resuscitation.

MR WAINWRIGHT: In this case he would actually have two consultants. This might work perfectly well on some occasions, but I am afraid I can envisage trouble.

DR BAINBRIDGE: This is why we are having a pilot scheme. It will be up to us to review the situation, and see whether the appointment made actually fits in reasonably well with the appointment that was originally planned. It is up to the consultants in the hospital concerned to plan the job specification very carefully. It is no good making an appointment and then hoping that he will fit in and work satisfactorily with the established consultants. The job specification will vary according to the local situation. There is no obligation on any group of consultants to provide a casualty consultant vacancy. All we are looking for is a number of situations throughout the country where this idea can be carried out on a trial basis.

Mr Spivey revealed in the ensuing discussion that he was concerned that the function of the casualty department, and therefore its staff, in the community had not been defined and argued that it was therefore premature to talk of job descriptions.

Mr SPIVEY: Is not all this talk about a job description 'pie in the sky' until you have defined the role that the hospital has to play in the community? At the moment, this is the least well-defined area in the whole thing and the hospital is taking more and more general practice work as $\mathrm{Mr}$ Denham has so well demonstrated. The new appointment is that of a hospital practitioner as opposed to a general practitioner. I think the point about what you call him, consultant if you like, is totally irrelevant to the fundamental problem.

DR BAINBRIDGE: I quite agree but nevertheless, within the existing set up, he either has to be a consultant or in a subconsultant grade.

Mr SpIVEY: Well change the set up in that way then. Everbody has said that this must be a revolution but there has been no revolution. All you are doing is fiddling with names.

DR BAINBRIDGE: There may not have been a revolution yet, but there certainly would be if you started fiddling around with the consultant grade!

Mr SPIVEY: You are not fiddling around with the consultant grade, you are fiddling with names and bending the situation in order to suit the circumstances; unless you can see this you will never get the organization that is required!

\section{A new grade for the casualty 'consultant'?}

For many people the idea of a senior casualty officer is an attractive one; the idea of calling him a casualty consultant and giving him the same status as a consultant in other specialties is, however, much less likely to be generally accepted. Much discussion therefore ranged on the idea of finding a new grade for senior casualty staff. Doctor Bainbridge in the following passage made it clear that the Department of Health had only reluctantly agreed to call this new appointment a consultant appointment and $a$ possible reason as to why this was the case was shown up by the later discussion.

DR BAINBRIDGE: I think that Mr Denham is advocating exactly what we are. His experienced sorter who can put a tube down is our casualty consultant. I was interested that he is concerned that the appointment of casualty consultant should not cause a block in the management of the patient. We are also extremely concerned about this and it is our contention that the job specification of casualty consultant should be very carefully drawn up to meet the local circumstances. We are thus advocating the same solution; what we are not agreed about is the title which we should give to these new appointees.

Mr Denham: As the Health Service is structured at the moment they should be either in a training or a career grade. They are obviously not in a training grade and yet they must at the same time be paid more in order to do the job. If we call them consultants, and pay them as consultants, then we are worried that they will produce this block in the management of the patient.

MR Rose: Surely what we are saying is that we have not got enough grades to accommodate these appointments.

DR BAINBRIDGE: What we are trying to do is create by this pilot scheme a new type of consultant. If the new appointments are accepted, presumably the Royal Colleges will get together and work out an examination which is suitable to the specialty, but this is looking a long way into the future. The only people we can appoint at the moment are people who have a lot of experience doing this kind of job.

Later in the same discussion period Mr Tansey raised the subject again.

MR TANSEY: I think it is very important not to call this chap a consultant, or otherwise it will give rise to the situation that Mr Denham is describing where he forms a block in the management of patients.

Mr CARo: Not at all, I think this has been a bogey all along. I do not think the people who are doing the work want to steal it from anybody else. I do not care what you call the man as long as he is equal with his colleagues and 
he sits on the committees and he can get some money. One of the troubles is that the senior hospital medical officer or senior casualty officer, whatever you like to call them, have not been at the source of the money and therefore the departments have been deprived, and nobody else has fought for them. No matter what you are called you have got to be equal.

MR WiLson: I notice the Todd report has not been mentioned so far. There is I believe in the Todd report a provision for a hospital practitioner.

DR BAINBRIDGE: There has in fact been pressure in this direction for some time and I think I can rightly say that the Joint Consultants Committee of the BMA cannot agree with the General Medical Services Committee on this point. If this difficulty can be resolved it would be welcomed with open arms by the Department of Health.

Mr DuRBIN: I would like to enlarge upon the point that Dr Bainbridge was making about the BMA organization. It is the GMS Committee which is blocking progress. I think this is a very serious thing. We are having our hospital service interfered with by people who are outside the hospitals. The Joint Consultants Committee is in favour of hospital practitioner grades; but this appointment is opposed by the General Medical Services Committee, and I see no reason to suppose that they will ever agree. Consultants should really organize themselves by joining the Regional Hospital Consultants Association in order that they can push their point.

Later Mr Witherow was able to give us some insight into the disagreement between committees within the BMA.

MR WITHEROw: The great problem with the new hospital practitioner grade is that the hospital practitioners and the general practitioners want different things. Because it is a new grade there is a great struggle to try to get the advantage for a particular group. The GPs are very keen that this grade should be restricted in numbers in order that their bargaining power for higher payment should be increased. They also want the grade restricted to GP principals so that the GP can go into hospital with a certain amount of status-in fact as a specialist in general practice rather than as the 'lacky' of a consultant. This gives rise, of course, to problems as far as junior hospital doctors are concerned since they may well not be prepared to be subordinate to a general practitioner.

Mr Denham: The chap that I want in the casualty department is a fellow who has got to know a great deal more than I do. In general I think a good general practitioner knows a great deal more than consultants. I would not mind if he was paid more than I am, but I do not want him doing the lot. I want him working in the casualty department only.

\section{Who will the new casualty consultants be?}

Having discussed the problems of creating a new specialty and then of creating a new grade of staff within that specialty, the conference also turned its attention to the type and calibre of staff which might fill the proposed vacancies in the pilot scheme.

Mr Denham: I do not think finding people to fill these posts will be quite as difficult as you think. I think there are general practitioners who are not particularly interested in the personal side of the job, getting to know the families and so on, who would be prepared to take it on. There are certainly some surgeons who have had difficulty in getting the Fellowship and are attracted by the hours of work, for this would surely, in some senses, be a 9-5 job, even if some of the afternoon sessions were swapped for night duty. I think there are a large number of people around who would take this job for around $£ 4,500$. I do not think it is a job for a man with the Fellowship.

DR AlDRIDGE: We have just advertised one of these jobs in the Birmingham region and $I$ think it would interest you to know that there were twenty-six applicants, all with Fellowships. Sixteen of them were Indians, and some were time-expired senior registrars.

Mr Rose: The question is 'did they come because they really wanted that job or did they come because they could get nothing else?'

DR AldRIDGE: Talking to those on the interviewing committee subsequently it became evident that those who were short-listed were interested in the job as a job.

Mr KNOWLES: We are just about to appoint a casualty consultant and I gather that there are no less than sixtytwo applicants for the job.

MR Denham: I do think, though, that you have to be awfully careful about whom you appoint. In one of our departments we have a doctor who told an orthopaedic consultant that he could not examine a fractured ankle because it was not out of the department yet.

DR BAINBRIDGE: This just emphasizes what I was saying about taking great care over making the appointments. If there is no suitable candidate, no appointment should be made.

\section{Management of the emergency patient by specialty divisions}

The preceding discussion demonstrutes the great anxiety felt by orthopaedic consultants and their senior registrars in the knowledge that a number of casualty consultants will now be appointed up and down the country. An alternative to creating a new specialist in casualty work is to create a better organization by which the existing specialty divisions can supervise their own emergency patients more satisfactorily. As has been previously stressed this will leave a number of patients, varying a great deal from area to area, who have attended the hospital because they cannot, for one reason or another go to their general practitioner. Any comprehensive organization must obviously take these patients into consideration.

Mr Steel and Mr O'Connor had brought up the possibility of management of the patient by specialty divisions early in the discussion. Mr Caro was quick to point out some of the disadvantages of this type of organization.

Mr CARo: Mr Steel made a suggestion that surgeons should look after the general surgical cases, physicians look after medical emergencies and orthopaedic surgeons after orthopaedic problems, but there is great difficulty in actually getting them there and even I, working in a busy London teaching hospital, find it impossible to get a soul to come down to the department. Unless you have ready availability of consultant services, then the system breaks down. It sounds alright in theory but does not 
work in practice. One of the responsibilities of the senior person within the department is to make sure that if he cannot provide the emergency services, then somebody is got out of the theatre, if necessary, to give this treatment. I think this is a very important function.

Mr Steel spoke later about his own organization at Stoke-on-Trent.

Mr Steel: I think to a certain extent the general surgeon and general physicians have abrogated their responsibilities. I feel they should be responsible for the primary care of the acute surgical and acute medical problems and in Stoke-on-Trent we have come to the agreement that we will provide a consultant orthopaedic surgeon to work in the department, not in the theatre, not in the clinic, but in the accident department itself each day of the week, and weekends too. Also our junior staff will be immediately available. The physicians and surgeons have agreed to provide, not the same service because they have a relatively small proportion of cases, but an undertaking that they will come instantly and see a patient if asked to do so. The emergency department should be used as a holding department for investigations, and possibly for senior opinion, since it is not usually necessary to transfer the patient immediately into the hospital.

Mr London was quick to point out that, before organization will work, one has to have co-operation.

MR LONDON: I regard interest, availability, and goodwill as the essentials of a good emergency department. If people will co-operate they will probably have a well-run department. If you have a well-run department you will probably get staff. I am sure this is the important thing and I think the established specialties find it difficult in many instances to attend to cases coming up at weekends, after dark, and on public holidays.

The next morning $\mathrm{Mr} \mathrm{O}^{\prime}$ Connor, congratulating $\mathrm{Mr}$ Denham on his contribution, suggested that here was an example of an orthopaedic surgeon beoming his own management consultant for his area casualty services.

Mr CARo: I think this demonstrates the point that $\mathrm{Mr}$ London was making yesterday; that is that a willing and keen consultant can go a long way towards solving the problem. However, in my hospital, we have the utmost difficulty in calling in a registrar, let alone a consultant, to the department. Occasionally Mr Denham's type of system may be successful, but in most situations it is impossible to achieve this degree of co-operation, and we must therefore look for an alternative solution.

Mr Denham described in detail how he arranged the orthopaedic cover in his own accident department mentioning in particular that his re-organization gave him time to teach his juniors in accident work.

Mr Denham: I think I have had a pretty unpleasant year trying to get the administration in Portsmouth to cope with this re-organization. My colleagues in orthopaedics have been fine; we have not had any problems there. Let us just say, as I stand at the moment, I could do with another two orthopaedic consultants. The general surgeons co-operate well since there is only a small general surgical unit in our hospital. The anaesthetists are quite outstanding and they have helped tremendously. I think the conception of an intensive care ward with an anaesthetist in charge is marvellous. The worries of the acute injury from the orthopaedic point of view, used to be quite considerable for me, not having had a good training in the management of head injuries and so on. The anaesthetists do all this marvellously. The chaps from the area organization come over and give us lectures, and they freely give us their advice on the telephone.

The real emergencies are usually an anaesthetic responsibility and, indeed, if we were to have more money for more consultants in our area, our first priority would be for anaesthetists, and second for orthopaedic surgeons.

Thus, Mr Denham pointed the way to an organization which would deal with the more serious accident cases. Mr Mulholland reminded us that it is the minor cases, by their sheer numbers, which often cause the most administrative difficulty. In this respect he again contrasted management by an orthopaedic consultant and by a new 'casualty consultant'.

Mr MulHolland: Surely the main reason for calling this fellow a consultant is that he is going to have clinical responsibility for $80 \%$ of the patients attending the department. Because we, as orthopaedic surgeons, are not prepared to deal with this $80 \%$ we must therefore appoint somebody else to do the work.

Mr Steel: I should be inclined to disagree most wholeheartedly. As orthopaedic surgeons we have got to be responsible for the smaller cases as well as the larger ones. People who come to the casualty department with sprains, cuts in the extremity, and minor fractures, are undoubtedly our responsibility.

Mr Mulholland: But you cannot possibly call them our responsibility when we never see them!

MR O'CONNOR: Gentlemen, I must intervene. It is your responsibility. You may never see the patient but you have delegated the responsibility to the individual who does see the patient. Responsibility is a boomerang-it cannot be delegated.

Thus, the responsibility of the orthopaedic consultant for all the minor trauma was emphasized. The responsibility of consultants in the other specialty divisions to the less urgent cases which came under their care was more difficult to envisage.

Mr FisHer: How many sessions do you envisage that your consultant will have to spend in the casualty department?

Mr Denham: I do not think it matters so much how many sessions they spend in the department but it does matter that they are involved in the running of the department. This would apply to the group I mentioned, orthopaedic surgeons, general surgeons, general physicians, and anaesthetists. I have not achieved yet the situation where we all have a fixed length of time in the department, but we do at least all work under the same roof with an out-patient clinic in the same building, so that there is an ease of consultation which might not otherwise exist. I think the idea of having consultant 
orthopaedic surgeons with three sessions in the casualty department, actually seeing the problems as they come in, is wrong, and is a waste of their ability. Not only this, but it does not improve the management of the patient. If you have orthopaedic consultants asked to see patients admitted in diabetic coma, you are asking for problems.

Mr Denham also emphasized the importance of consultants in other specialty divisions for the administration of the casualty department. He was asked by Mr Witherow if he felt that casualty departments could be more satisfactorily run by a committee with a casualty consultant at its head.

Mr Denham: I think you could arrange it as you like. In Portsmouth $80 \%$ of the cases are an orthopaedic responsibility and it devolves upon the orthopaedic surgeon to manage the department. I think it would be perfectly satisfactory to have a management on a rotation basis, perhaps through the anaesthetist, general surgeon, general physician, and orthopaedic surgeon. Each would take 1 year of responsibility on the rota. I also think a committee administration might be perfectly reasonable. I do not mind who is responsible, but somebody has got to be responsible. It would seem that the orthopaedic surgeon is the most satisfactory man to take this responsibility at the moment.

MR WAINWRIGHT: Stoke is envisaging a committee to manage this problem with a chairman sitting for 3 years.

\section{Training in casualty departments}

Early on in the discussion Doctor Bainbridge had emphasized that the new appointment of casualty consultant would have, if it was approved, ultimately to be backed up with the appointment of senior registrars and registrars in training within the casualty department. Ultimately, the new casualty consultant would have been specifically trained for the job. With a lot of discussion, previously reported, centering on GPs taking more responsibility for minor cases in group practices and health centres it was natural that some of the discussion should have centered no trainee GPs receiving tuition in casualty work.

Mr Brown: Could I ask Dr Cull if there is any point in training general practitioners in the casualty unit before they start in general practice?

DR Cull: I do not think working in the casualty department is good training for general practice.

Mr BRown: Would, in the training programme for general practitioners, a short period of supervised work in the department be of value?

DR Cull: I would accept that.

The next morning this point was taken up by Mr Denham.

Mr Denham: I think there is a lot of educational work to be done in all specialties as far as casualty work is concerned. I was very surprised to hear somebody say yesterday that casualty work was not good training for general practice. I think it is extremely good.

DR Cull: It was I who made the point yesterday that, in the present situation, it is not good general practitioner training. That is not to say that I do not agree with you. It could be excellent training.

Mr Denham: You are absolutely right. A general practitioner trainee working in one of our casualty departments reported to the regional board, the average time spent by the consultant in charge of his department. It worked out at 7 minutes per week.

\section{Project report}

Discussion groups were organized to discuss six projects which later were reported to and discussed by the conference.

\section{Project 1}

To discuss the executive management of casualty services as opposed to the clinical management.

\section{Report}

We considered the casualty departments of district general hospitals. The control of the casualty department should rest with the hospital as a whole working through a committee which should consist of no less than a consultant surgeon, a consultant physician, an orthopaedic surgeon and an anaesthetist. The committee would be empowered to elect a chairman on a yearly basis. The day-to-day control of the department should rest with a man, probably of subconsultant grade, working within the department. He should be of a subconsultant grade in the present structure simply so that a bad appointee could be replaced. The bigger hospitals would need to add to this committee, a psychiatrist, an eye specialist, a dentist and a gynaecologist as the local need arises. By this means the responsibility for the accident and emergency department is placed firmly within the hospital as a whole. The orthopaedic and traumatic surgeon would be the most likely chairman because of the proportion of cases which fall in his specialty. The day-to-day control is a difficult decision. It is an important post and must of course be well paid and this person must have the full support of the committee backing him up. In other words, he must be able to call junior staff when necessary out of operating theatre or a clinic to provide the necessary cover in emergencies.

\section{Discussion}

DR BAINBRIDGE: The medical assistant has the same security as a consultant and therefore he will be in exactly the same position as the one you have already.

MR WITHEROW: Is it not true that the medical assistant is appointed with an annual review times two?

Mr Elson: One of the practical problems of organization in hospitals is to get any group of consultants to coordinate. It is possible to have a leader or chairman who holds universal respect. The danger of a committee is that you have one man whose personality will upset the balance. To run the casualty by committee is naive. One of the problems of electing a chairman on an annual basis will be the ability to change present contracts.

Mr O'ConNOR: What this syndicate is trying to highlight is that the emergency department is the corporate responsibility of the hospital.

Mr Elson: This is a naive concept, because, unless you have one person who has something to fight for, then you 
do not achieve anything. In the present hospital structure, corporate bodies do not battle in quite the same way.

MR HARRIS: Whoever is in administrative charge must have access to the general policy-making apparatus of the hospital. This is one of the problems of the casualty at the present time. The casualty department now is in isolation. I would like to see involvement of other specialties according to the proportional clinical responsibility.

MR O'CONNOR: I agree that the emergency department should not te left in isolation and that other departments should be made more responsible.

MR HARRIS: I think the cog wheel system has proved an effective way of dealing with this problem especially where there are personality problems between consultants.

\section{Project 2}

What should the relationship be between the emergency department and community medical services?

\section{Report}

This problem was discussed in various sections, first the accident service. The variation of the involvement of the interest of the general practitioner in the primary care of accidents was stressed. It appeared that in the more peripheral areas where the hospital services were not easily available, the general practitioner was more interested in and involved himself greatly in primary care of minor injuries. It was felt that if more facilities were available to the practitioner, for instance, access to sterilized instruments and theatre facility, they would be willing to do very much more of this work themselves.

It was felt that the first aid treatment and road-side treatment of major accidents was less important, with respect to the practitioner, in that ambulance facilities were usually very quickly available and the time involved in transporting these cases to accident centres was not great. In some areas however, the general practitioners are part of the force available in the primary care of major accidents and in certain areas the regional board or hospital management committee assist in the equipment of these practitioners. The importance of the rule of training of these practitioners was stressed. It was felt that the person in administrative charge of accident services should actively seek out the assistance of the practitioners and encourage them to take part.

Non-accident emergencies we classed in two different groups. First those that are referred by the practitioner to the hospital for a specialist opinion. It was felt that these cases were not a problem because the specialist facilities were already readily available in the hospitals. The group of patients who present themselves to the hospitals without seeing the practitioner first are a much greater problem. The general practitioners themselves deplore this increasing habit of the public. It was felt that such people are best initially seen by a 'generalist'. There was little agreement as to who this 'generalist' may be, but some favoured the so-called 'failed' specialist who, even though he may not have the appropriate specialist tickets, may be nonetheless a competent general doctor. It was felt that this was a full-time job and that there was no place for a general practitioner doing part-time duty in the hospital in this role. The difference between a person in admini- strative charge of the casualty department and a person in clinical charge of the patient was stressed.

Suggestions made to minimize this problem were, the education of the public with respect to their duty to approach their own practitioner initially. It was also suggested that a period in the accident and emergency department would be useful in the training of a general practitioner and, in fact, useful in the training for any specialty. It was felt that this was not just a means of getting extra hands into the accident and emergency department but rather a useful training ground. It was also suggested that a health centre, actually in the same grounds as the hospital, might lighten the load on the hospital, the various facilities of the hospital being available to the general practitioner. It was apparent, however, that the enthusiasm from the general practitioners varied greatly from area to area.

\section{Discussion}

Mr WILSON: Health centres will be staffed by a number of group practices. It is unlikely that general practitioners will agree that casual patients should go to health centres in the hospital grounds as this will institute an unfair advantage. It would be more profitable in fact to have health centres spread round the periphery rather than at the centre.

Mr Witherow: The problem of conscription has been raised for people doing general practice to go into the emergency department. Could we turn the question round and ask if people in hospital should also offer to do a period in general practice.

Mr McLain: The group did not discuss this but $I^{\circ}$ personally would feel that a period in general practice would be of great value.

MR HAMPSON: I agree that hospital doctors would gain by going into general practice for a period. But would the general practitioners be prepared to cope with extra hangers-on? And what do you think ought to be done to encourage them to take on this added load?

DR CULL: I take on this training work both with student social workers and nurses from the teaching hospitals to show them what general practice means. It does mean that my colleagues have to take on an added burden on that particular day. It absorbs a lot of time but I am sure many general practitioners would be prepared to do this.

\section{Project 3}

What should an orthopaedic and traumatic surgeon's responsibility be in the management of an emergency department?

\section{Report}

(1) Clinical responsibil'ty

It was agreed that the orthopaedic and traumatic surgeon should be clinically responsible only for work falling within his specialty.

\section{(2) Administrative responsibility}

It was decided that authority for the administration of these departments must reflect the clinical responsibilities they present. Thus, in pure accident centres traumatic surgeons would assume full administrative responsibility. 
In the more usual departments dealing with mixed emergencies of a readily classifiable type, administrative responsibility should be shared between the traumatic and orthopaedic consultant and such other consultants as were involved in clinical responsibility in the department.

(3) In departments where the trauma content was low the traumatic and orthopaedic surgeon might bear no administrative responsibility for the running of the department. Possibly in these circumstances a casualty surgeon of consultant status might assume administrative responsibility.

\section{Discussion}

Mr CARo: There is this problem of a split between the clinical and administrative responsibility. Who is responsible for the patient who is wrongly sent away with a condition such as a headache or abdominal pain? You say they should not be the responsibility of the orthopaedic surgeon but of the general physician or general surgeon. If you do not do this then you put the responsibility on the junior staff. The basic problem is who is responsible for this senior house officer's action.

Mr O'CONNOR: His immediate superior.

Mr CARO: He has not got one. If you are in a casualty department with three or four senior house officers with an orthopaedic surgeon in charge he may only be in charge in an administrative capacity.

MR ROSE: The senior house officer is a doctor and if a patient is sent away wrongly then he is the only person who can take full responsibility. This is a clinical responsibility. This split between the clinical and administrative responsibility is not in question. Administrative responsibility means dealing with equipment, beds etc.

Mr ELSON: I think the senior house officer post is a training post.

Mr Rose: The senior house officer is a registered practitioner and in the law courts he is responsible if no one else has seen the patient.

Mr ELSON: A senior house officer is working within the hospital. Fifty percent of the responsibility will be that of the hospital. It is the hospital, through a consultant, who has said that this man is fit to make this type of decision. The responsibility must come back to his consultant.

Mr Rose: You have to face up to the legal situation. If the hospital has been irresponsible in not providing the equipment for a servant to do his job, then it takes either total or part responsibility; but if that doctor turns the patient away without consultation then it is his responsibility alone.

Mr O'CONNOR: This is the only situation in the world where the actual individual is held legally responsible. In business the individual is not responsible, but the institution.

\section{Project 4}

What are the clinical responsibilities of the orthopaedic surgeon in the emergency department?

\section{Report}

The BOA survey clearly showed the dependence of emergency departments for their staffing requirements on the senior house officer and registrar grade. To supply sufficient trainees for all consultant surgeon posts in this country 100 senior house officers would be sufficient. To run the departments we know that we need approximately 650 . It was asked if the consultant orthopaedic surgeon had a part to play in dealing with the front line workload. It was necessary to consider the need for consultants in emergency medicine or surgery.

There was a need for good primary care of all injured patients; this involved close consultant involvement for their treatment. This might be supplied by the presence of consultants in the department. There was often difficulty in asking a consultant or registrar to leave a busy clinic to deal with an emergency.

Possible ways of involving the orthopaedic surgeon were described. In Portsmouth, the orthopaedic surgeons had a week of total commitment to trauma every third week. In Leeds, the orthopaedic surgeon 'on-take' spends his whole day in the emergency department, probably doing a clinic during the morning or afternoon, but with no commitment to any other duties.

The question of allocating some sessions to emergency work - it was suggested that a surgeon doing $50 \%$ trauma would have to fit in to his four-and-a-half sessions, one-and-a-half of operating, one ward round and one clinic, leaving only one for direct supervision. The appointment of more consultant surgeons had some time been baulked locally because of fears of dilution of experience, but it was fair to say that often lack of facilities had been the reason. The casualty department was still underfunded and understaffed.

It was thought that the present junior orthopaedic surgeons were both trained and willing to take a more active part in the treatment of trauma than their predecessors.

The appointment of casualty surgeons was discussed. There was an advantage in the constant presence of an experienced consultant during the hours when the great majority of patients attended. In Leeds, in a department run by such a consultant, staffing difficulties were virtually unknown.

One of the merits of having clinical control of such departments in the hands of orthopaedic surgeons was that juniors were more likely to follow their cases through with consequent training advantages.

Finally, the chairman asked the orthopaedic trainees and surgeons present whether they would (a) be prepared to take a more active part in the work in casualty and $(b)$ whether they approved of the appointment of casualty surgeons. Their answer to (a) was a unanimous 'Yes' and their answer to (b) a unanimous 'No'.

\section{Discussion}

Mr SPIVEY: We should discuss the shortage of staff and not the reduction in working hours. A senior house officer working 3 or 4 nights in succession evidently becomes tired and will make mistakes. He has every justification for asking for shorter hours.

MR WAINWRIGHT: I think that, if orthopaedic surgeons wish to run emergency departments, then they should ask for more orthopaedic consultants to be created. It is sometimes said that we cannot appoint more consultants because there is insufficient operating time. I think this is a myth and can be improved by simple re-organization. 
If we are going to do this work, we need more people and more people at consultant level. Do not be put off by arguments about lack of facilities.

\section{Project 5}

Staffing patterns-what should be aimed at?

\section{Report}

The problems revolved around two subjects, the shortterm and the long-term problems. The long-term problem involved a career structure of casualty consultants, whose prime function would be to teach. There were various proposals for the solving of the short-term staffing deficit; the majority were in favour of a compulsory rotation preregistration period to include 6 months in casualty. However, it was felt that junior hospital doctor militancy might render this difficult. It was generally agreed that efficient health centre services were going to be an essential adjunct In the meantime, the most immediate problem will have to be solved, if necessary, by paying junior staff at GP rates.

Although a 2-year delay might be anticipated before the benefits of the new casualty consultant system would be felt, it was hoped, by the Department of Health, that following announcement of the scheme, an upsurge would ensue.

\section{Discussion}

Mr CARo: I think this is one of the most realistic reports we have had. It really comes to grips with the problem.

Mr Witherow: I want to scotch the myth that the crisis in the staffing of casualty departments has resulted from a cutting off in the in-flow of overseas doctors. In fact, there is a net annual increase in the overall pool of doctors in this country of 600 or 700 . Figures for the last 2 years, the years in which the change in the overseas regulations bore on overseas doctors: in 1968, there was an increase in home doctors of 350 , and from overseas of 447 adding up to 797 ; in 1970 there were 508 home doctors and 162 overseas doctors, so that the overall change in the increase was only in the nature of 150 . So it is not an enormous stopping of the flood gates of eager people coming in to do casualty work from abroad.

MR CARO: Some other factor is operating, either people are doing less time or they are less willing to work in casualty departments and it might be useful to have a look at that aspect of things. One factor that may be important, and this was mentioned to me by a teaching hospital consultant, was that 5 years ago most medical students seemed to want to become consultants. Nowadays, $80 \%$ of them want to become GPs and of course this has cut down the number of people who want to do surgery.

MR O'CONNOR: I think Mr Witherow's point has to be looked at very carefully The main factor is probably lack of job satisfaction. There is no question of a closure of flood gates.

DR Pledger: The total number of posts, that is the number of posts for which finance is available in trauma and orthopaedics, has actually gone up by $200 \%$ in the last decade and there can be no doubt that money has gone into the establishment of these posts. As far as the staffing of these posts is concerned recent figures show that three times as many overseas doctors are coming into the country per month now as were coming 12 months ago.

DR BAINBRIDGE: I think probably the attachment schemes are working better now.

Mr DuRBIN: I think they have had to double the number of posts because of the decrease in the hours of work. That teaching hospitals are finding it difficult to get staff in casualty departments is a reflection on the fact that they can no longer say 'Do 6 months in the casualty department and we will give you an HP or HS job'.

MR ELSON: I think some of the difficulty in the teaching hospitals is due to the fact that they restrict the number of staff which they are prepared to employ. I mean by this that they may restrict the staff to their own graduates or those from surrounding hospitals.

DR BAINBRIDGE: The other thing is that certain teaching hospitals in London are running on agency doctors.

\section{Proiect 6}

How should the training of staff be organized with special reference to the non-surgical disciplines?

\section{Report}

It has been said that the low morale of junior staff working in emergency departments has resulted from many deficiencies in the organization and management of these departments and we define these deficiencies which affect training as follows: firstly lack of supervision, secondly lack of personal consultant involvement at many levels of management, thirdly lack of direct instruction, fourthly lack of rotation schemes in and out of the department. We felt that the objectives in the training of staff within the accident and emergency units should be: (1) To give training in all specialized practices within that department and (2) to provide staff for the department. The department itself should be managed by a consultant. A training cannot be looked on without taking into account the problem of staffing. Most staff working in these departments are passing through on rotation schemes whilst training for an established medical or surgical specialty. Because of this we felt that an extensive training scheme directed towards the production of a casualty consultant was not possible at present. This was supported by the fact that disciplines of casualty were so varied that no trainee would fulfil the regulations for higher degrees without spending an inordinate length of time in training. Training should be part of overall training for an established medical specialty, i.e. general surgery or orthopaedics. We shall seek to teach a standard of competence in the management of acute surgical, medical and traumatic emergencies. It was felt that casualty work should be an essential prerequisite of medical registration, and should be done as a third job for registration. Whether doing the job before registration or for a period in rotation whilst training for surgical specialty, the training should have consultant supervision. A consultant should demonstrate emergency procedures such as intubation, insertion of chest drains and perhaps burr holes and tracheostomy. Training in the management of medical emergencies should similarly be under consultant supervision. A 
consultant should be available for advice for example to give guidance in the management of less severe trauma such as hand injuries. We would envisage a post lasting 6 months during which a trainee would attend lectures and clinical demonstrations or specialties allied to this work for example psychiatry, general surgery, management of overdoses etc. At the end of this period, he will be familiar with emergency procedures and capable of recognizing the more subtle problems of disabling injuries. The emphasis in this report has been placed on the management of surgical problems in casualty because of the figures which demonstrate that in most places the major part of the work load is of a surgical nature. We feel that this emphasis is correctly placed. The problems of training a casualty consultant would involve much interchange and interplay with other departments and we felt that this might disrupt training in other specialties. That training required time was emphasized, and that if you are going to give time to training then more people have to be involved toth at a consultant level and also in the junior grades in the department.

\section{Discussion}

Mr SPIVEY: I do not think that conscription is justified just for the sake of filling a job.

DR BAINBRIDGE: I think it would be quite wrong to conscript doctors into the department. If they are to come in, it should be part of the vocational training developed by the Royal Colleges. The purpose of the casualty surgeons' pilot scheme is to see if we can find a way of improving the training potential in the department. If training can be made to work, the job becomes more attractive.

MR RICHARDSON: Is it absolutely essential for people working in the accident service to take a higher qualification. If you have provided good training, with in-training assessment without the necessity of taking a formal examination, you might attract a greater number of people to the job.

DR BAINBRIDGE: This is a matter for the Royal Colleges.

Mr ELSON: If you want the right kind of casualty surgeon, then he has to go through the examination hurdle which at present is the only method of testing the necessary intellectual calibre. This is necessary because he has to stand on an equal footing with other consultants within the hospital. He has to be a specialist, and he has to have all the necessary qualifications and at the same time to be an excellent teacher.

Mr Markham: I do not think people will do this job voluntarily unless they are passing through to, say, general practice. I think they will have to be conscripted.

MR O'CONNOR: We must consider alternative methods used outside this country where rotating internships through numerous specialties are undertaken.

MR CARO: I have been a little disillusioned with teaching. I have found people working in the department reluctant to make the special effort to attend specially arranged teaching sessions.

MR WITHEROW: I think that the situation is going to get infinitely worse during the next 5 years. This is for two reasons:

(1) The drying up of people coming from abroad.

(2) Increased rigidity in training schemes being imposed by the Royal Colleges, particularly the Royal College of General Practitioners. It is going to be very difficult for us to get casualty trainees. One of our most important tasks should be to persuade the Royal College of General Practitioners that everyone who is going to get the diploma of their college should have experience in an emergency department.

Mr BROWN: We should perhaps question, as $\mathrm{Mr}$ O'Connor has done, the two 6-month periods of preregistration and instead have the rotating internship which will give a very much broader base for deciding on future careers.

DR Cull: The Royal College of General Practitioners have shied away from training in the emergency department because of the lack of supervision and the lack of teaching. The College would be only too glad if they could be assured of these facilities.

MR HART: In Australia, where we have the rotating internship, it is felt that the detection of the ill patient is best learnt in the emergency department and it is incorporated in the rotating scheme. 